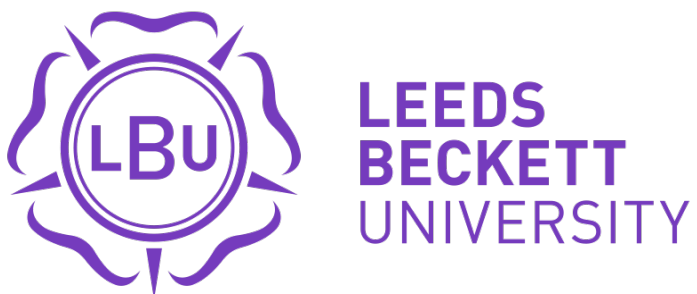

\section{Citation:}

Lofthouse, RM and Thomas, U (2014) Mentoring student teachers; a vulnerable workplace learning practice. International Journal of Mentoring and Coaching in Education, 3 (3). pp. 201-218. ISSN 2046-6854 DOI: https://doi.org/10.1108/IJMCE-03-2014-0010

Link to Leeds Beckett Repository record:

https://eprints.leedsbeckett.ac.uk/id/eprint/4010/

Document Version:

Article (Accepted Version)

The aim of the Leeds Beckett Repository is to provide open access to our research, as required by funder policies and permitted by publishers and copyright law.

The Leeds Beckett repository holds a wide range of publications, each of which has been checked for copyright and the relevant embargo period has been applied by the Research Services team.

We operate on a standard take-down policy. If you are the author or publisher of an output and you would like it removed from the repository, please contact us and we will investigate on a case-by-case basis.

Each thesis in the repository has been cleared where necessary by the author for third party copyright. If you would like a thesis to be removed from the repository or believe there is an issue with copyright, please contact us on openaccess@leedsbeckett.ac.uk and we will investigate on a case-by-case basis. 


\title{
Mentoring student teachers; a vulnerable workplace learning practice
}

\author{
Abstract \\ Purpose \\ The purpose of this research is to develop an understanding of mentoring as a workplace process. The mentees \\ are post-graduate student teachers hosted in placement schools. The research aims to explore the experiences \\ of key participants in a policy context where the role and scale of school-based teacher training is expanding \\ rapidly.
}

Design / methodology / approach

This is an interpretative case study of mentoring practices assigned to a secondary level initial teacher training partnership, with the mentors being subject teachers working in school departments which host post-graduate student teachers. The case study was investigated over two years and included focus groups, interviews, questionnaires and content analysis. Participants were student teachers, their mentors and both school-based and university-based tutors.

Findings

Positive experiences of mentoring are not universal. Mentoring interacts with the required processes of monitoring and reporting and in some cases the power structures associated with these processes conflict with the less performative aspects. However when mentors are offered evidence of student teachers' perceptions and theoretical constructs of mentoring as practice they can start to recognise that it can be enhanced.

\section{Practical implications}

The quality of mentoring in initial teacher education will take on even greater significance in jurisdictions, such as England, where the role of workplace learning is strengthened as a result of changes of government policy.

Originality / value

The outcomes of this study will be relevant to policy makers, school-based mentors and system leaders for teacher education - whether school or university based. 


\section{Introduction}

Mentoring as an educational practice is recognised as complex and taking many forms (Brondyk and Searby, 2013). This is illustrated by the multiple variations in its stated functions and objectives for both organisations and individuals; the intentions of participants; the perceptions of the roles of mentor and mentee held by themselves and by others; and the balance of the processes of support, instruction, and gate-keeping adopted. This study is focused on mentoring within school-based placements that post-graduate studentteachers undertake during their Postgraduate Certificate in Education (PGCE). The initial teacher training provider is a university in northern England which works in partnership with local secondary schools. The term 'mentor' refers to a subject teacher who works with a student teacher for the duration of his/her teaching placement. In addition to the support provided by their mentor each student teacher has additional academic and workplace support from university tutors and professional tutors (usually senior teachers in school who act as co-ordinators of school-based training). The student teachers are also expected to gain Qualified Teacher Status (QTS) by meeting Teacher Standards which are defined by the UK government's Department for Education (DfE); and the award of QTS is judged by the subject mentor, professional tutor and university tutor as a collective. Thus, mentoring as a practice plays a pivotal role in the workplace learning experience and assessment of student teachers.

This study was undertaken during a period of a significant policy shift to school-led teacher training in England, centred on the introduction of the 'School Direct' route. In summary this new route enables a school to bid directly to a government agency for trainee allocations and to recruit trainee teachers who apply directly to them as a lead school (often on behalf of an alliance of schools). The lead school is expected to make its own strategic and operational decisions regarding the nature of training, workplace experience and qualification gained by its trainees. This deliberate shift in the balance between universities and schools has altered the roles and responsibilities of the key participants. It has also more explicitly linked the process of teacher training to the direct recruitment of newly qualified teachers within individual schools and their alliance schools. These changes are being superimposed in workplace cultures that are largely performative. Over a decade ago Ball (2003) suggested that school teaching in England over the previous twenty years had existed in a culture of performativity; 'a mode of regulation that employs judgements, comparisons, and 
displays as a means of incentive, control, attrition and change' (p.216). He noted that this culture is characterised by high stakes testing, attainment-driven school and national league tables, a dominant inspection regime and schools-generated 'self-surveillance' which has led to the micro-management of teachers' performance. In a more recent publication (Ball, 2013) reported further intensification of these practices. It is important to note that initial teacher training partnerships are also subject to systematic performance measures, with the allocation of quotas for courses closely linked to quality indicators as defined by the DfE and assessed by both the National College of Teaching and Leadership in England, and as inspected by Ofsted (the Office for Standards in Education, Children's Services and Skills).

The focus of this research is the practice of mentoring as perceived by the key participants outlined above (student teachers, school-based mentors and professional tutors), and the backdrop is the changing training context.

\section{Conceptualising mentoring practices within workplace learning}

Our research aims to understand mentoring of student teachers as a practice-based learning process situated within the school as a workplace, conducted by mentors who are embedded in that workplace, and for the purposes of sustaining the working practices and staffing of that workplace. Thus, to conceptualize mentoring practices we look to research in workplace learning as well as mentoring per se. Mentoring is well explored in both professional and academic literature (for example by Fletcher, 2000, Burley and Pomphrey, 2011 and Fletcher and Mullen, 2012); these authors and their contributors take good account of the context of mentoring, either in workplaces or educational settings. Other researchers seek to consider the relationships between mentoring and other workplace roles and responsibilities (often undertaken in tandem). Wilson (2014), for example, using Cultural-historical activity theory (CHAT) recognises that the primary goal of a teacher is ensuring pupil achievement. As a result any activities they undertake related to teacher education, such as taking the role of mentor, can be diverted to this primary goal of pupil achievement, away from the goal of enabling the student teacher to develop. Through a different lens Thornton (2014) investigates the extent to which mentors of new teachers in the USA can be viewed, and developed, as 'educational leaders'. 
She concludes that the potential for this is largely determined by the levels of training and support that mentors are given, the underlying school culture, and the views of mentoring held by school leaders.

If mentoring works to support practice-based learning related to the workplace it is valuable to consider Billett's (2011) examination of three dimensions of practice-based learning. These are the practice curriculum (how the learning experiences are organized); the practice pedagogies (how the learning experiences are augmented); and the personal epistemologies of the participants (the means by which the individuals come to engage). These dimensions can be seen as relevant to PGCE students during their school placements. Billett also notes the duality of the workplace experience, being dependent on the quality of the invitation to learn from the workplace and on the extent to which the learner chooses to engage. He confirms the two Dewian concepts of the goals for vocational education - to help learners identify prospective occupations or specialisms and to enable them to gain occupational capacities. Billett adds a third goal of helping learners to sustain occupational competences to facilitate further professional development. When viewed from this perspective it is clear that mentoring student teachers ought to frame and scaffold productive, purposeful and expansive practice development and professional learning if the potential of workplace learning is to be maximised.

In his discussion of workplace learning Eraut (2007) proposes a typology of early career learning in which he identifies three key features/characteristics. Firstly, engagement in work processes typical of the profession (for a student teacher this would include planning and teaching lessons), secondly being involved in learning processes which are offered at or near the workplace (such as being mentored or attending training) and thirdly, purposefully undertaking learning activities located within work or learning processes (such as asking questions and learning from mistakes). While Eraut looked between professions and workplaces to draw broad themes, an additional, profession-specific perspective was offered by Imants and Van Veen (2010) and Imants et al. (2013). They explored teacher learning as workplace learning and identified six factors determining the integration of teachers' learning and work:

(1) the learning potential of the task,

(2) opportunities for feedback, evaluation and reflection on the outcomes of work actions,

(3) formalization of work processes,

(4) employee participation in handling problems and developing work processes, 
(5) learning resources,

(6) shared norms (Imants and Van Veenan, 2010), as cited in Imants et al., (2013).

Each of these factors has relevance within mentoring, particularly in contexts in which student teachers spend extended periods of time within placement schools and are deliberately trained as potential employees of that specific workplace, as they are in School Direct (the new English route in to teaching outlined above).

Mentoring of student teachers is a learning process by design, but it also has the potential to facilitate access to work processes. For example a mentor may act as a gatekeeper determining whether a student teacher can teach certain classes. Mentors also form part of the context within which a student teacher is more or less likely to engage in learning processes. As such mentoring has the potential to either afford or constrain the student teachers' workplace learning outcomes.

Hobson and Malderez (2013) alert us to one such constraint. On re-analysing data from two research projects related to teacher education in England between 2003 and 2012, they found evidence of what they termed 'judgementoring'. They define judgementoring as,

a one to one relationship between a relatively inexperienced teacher (the mentee) and the relatively experienced one (the mentor) in which the latter, in revealing too readily and/or too often her/his judgements on or evaluations of the mentee's planning and teaching, $[\ldots]$ compromises the mentoring relationship and its potential benefits. (Hobson and Malderez, 2013, p.90)

They propose that the development of judgementoring relates to failures at individual, institutional and policy levels to create appropriate conditions for effective mentoring. It seems highly likely that mentoring practices are being cultured by the performativity agenda of the schools as workplaces referred to above. The limiting impact on mentoring practices of judgementoring can perhaps be explained using the theory of practice architectures (Kemmis et al., 2011). This theory is applied by Kemmis and Heikkinen (2012) who offer it as a lens through which to view mentoring practice in their exploration of teacher peer-group mentoring in Finland. They view practice as socio-cultural, rooted in traditions of the context, but articulated by the participants. The theory proposes that practice is composed of three dimensions, which they call 'spaces' (hence the use of the word 'architecture'); these are social space, termed 'relatings', physical / temporal space, termed 'doings', and semantic space, which they term 'sayings'. The characteristics of these 'spaces' 
have the potential to be altered by conditioning socio-cultural contexts, and as such mentoring can be perceived as a practice in flux at a time when policy-changes revise the system and nature of teacher education.

\section{The context of our research: what and why?}

In his review of research on mentoring Clutterbuck (2013) concludes with recommendations for future research in this area; we use these recommendations to define the context and purpose of our research. He asserts that research must clearly articulate the type of mentoring relationship being measured, and he asks that the context is clearly explained. The mentoring practices being investigated in this case study are those assigned to a secondary level initial teacher training partnership. The mentors are subject specialists working in school departments within which post-graduate student teachers are hosted for the workplace learning component of the programme. Student teachers spend the equivalent of 24 out of 36 weeks in two schools, and in both they are first inducted and undertake observations and then take on teaching commitments.

Clutterbuck goes on to state that the process, outcomes and relevance should also be identified in mentoring research. In this case study the process is based on one-to-one, face-to-face mentoring undertaken in the context of the placement schools. The mentoring role includes induction, supervision of teaching, feedback and support for progression, training in key teaching practices, and assessment of achievement against the standards required for qualified teacher status. Mentors are thus recognised as subject specialists, vocational instructors, critical friends and gatekeepers. This research aims to investigate how participants experience and perceive both the processes and outcomes of the mentoring practices that they either lead or engage in.

Clutterbuck's final recommendation is that the 'so-what?' question is answered through the research; in other words a consideration is made of its relevance not simply as an academic artefact but in relation to developing mentoring practice. The quality of mentoring in initial teacher education will take on even greater significance in jurisdictions, such as England, where the role of workplace learning is strengthened as a result of changes of government policy. If the quality of student teachers' placement experiences is to be ensured then mentoring must be secured as a positive practice for all participants. The outcomes of this study will be 
relevant to policy makers, school-based mentors and system leaders for teacher education - whether school or university based.

\section{Methodology}

This research is undertaken within an interpretative paradigm and is influenced by one author's role as a teacher educator, and by a desire to understand mentoring in schools as workplaces through the experiences of key stakeholders within that context. The stakeholders are:

- the student teachers, all of whom are on a 36 week post-graduate professional course to qualify as secondary teachers, and who spend 24 of these weeks in two school placements;

- their subject mentors, all of whom are qualified teachers, but who could have been teaching between two and thirty-two years and have different levels of mentoring experience; mentors are responsible for allocating and supervising their allocated student teacher's teaching experience, providing feedback and assessing their progress;

- those who manage the mentoring process, both university tutors and school-based professional tutors, who provide the university Master's level education and the work-based training opportunities to student teachers, and training for mentors, as well as providing general oversight and support.

By drawing on the perspectives of these actors we are seeking to articulate the experiences of mentoring, to further theorize mentoring and to begin to explore how it can be improved. A case study methodology has been adopted in order to examine the experiences and perceptions of mentoring practices within one initial teacher education partnership at a time when the nature of that partnership is changing. Case studies allow researchers 'to understand a real-life phenomenon in depth' where 'the contextual conditions' are important (Yin, 2009, p.18). 
Our analysis of the data collected includes both generalised themes, but also the voice of individuals, thus reflecting the variety of personal experiences within this case. We present our findings in order to encourage further 'analytic generalisations' (Yin, p.38) from others who have experience of similar cases.

Throughout this paper, the term 'student teacher' is adopted by the authors rather than 'trainee', as members of the case study group were all registered PGCE students. The central research questions are:

- How do student teachers, their mentors and tutors experience mentoring, and what do they perceive as the affordances and constraints in creating a positive outcome?

- How can mentoring be theorised as a practice; and to what extent might this support the participants in engaging positively in it?

The research was conducted over two academic years (2011-13) and involved two cohorts of student teachers. The first year was a scoping year with a focus on understanding the affordances and constraints that impact on mentoring practices. The second phase of the research was not initially planned but was included to validate and extend the first year's findings, and to ensure that as many mentors' and students' voices as possible were considered. The student focus groups that took place in this second phase were divided in to 'core' (English, Science and Mathematics) and 'non-core' (Modern Foreign Languages, Geography, History and Religious Education) subjects. This decision was taken because the data which emerged from year 1 suggested that there might be an impact on mentoring within core subjects; in that the student teachers and their mentors in these subjects expressed greater anxiety about pupil attainment and therefore student-teacher performance measures, than seemed typical in non-core subjects. This is possibly because although the term 'core subject' is now a historical one, relating to the national educational policy which resulted in the 'National Strategy' for secondary education, English, Mathematics and Science have remained high-stake subjects in relation to published school league tables. 


\section{Data collection and analysis}

\section{Phase One}

Initial telephone interviews were undertaken with the Professional Tutors in order to obtain information about the context within which the student teachers and their mentors were working. These were followed by focus group interviews with the student teachers, during which the experience of being mentored was discussed. In each set of interviews, semi-structured schedules were used. These provided the interviewer with a structure that was focussed on the research questions but also allowed for 'deviation from the agenda' which was both 'expected and accepted' (Limerick et al., 1996, p.451). All of the interviews were recorded and transcribed. During the focus group interviews the main ideas being expressed were noted on large sheets of paper and the interviewer validated these with the participants prior to concluding each interview. The interview transcripts were analysed using the 'editing organising' approach proposed by Miller and Crabtree (1999, p.22).

Each transcript was read by the researchers (co-authors) and meaningful units were identified. These units were then organised into categories based initially on the ideas identified during the focus group interviews and then using the theoretical framework offered by the Theory of Practice Architecture - 'sayings', 'doings' and 'relatings' (Kemmis and Heikkinen, 2012). Content analysis of the students' assignments and the questionnaires followed the same analytic approach. The assignments were deemed relevant because they included a section which required them to reflect on their experiences of learning through professional dialogue, including mentoring) Once completed the findings were disseminated and discussed by a group consisting of university PGCE tutors and the school subject mentors. Examples from these discussions have also been included within this paper

\section{Phase 2}


Two student teacher focus groups took place in Phase 2 with students about to complete their teacher training year. The theme for these focus groups was the students' perceptions of the influence of the performancebased culture on their PGCE year; with the students invited to critique their experiences in relation to the concept of performativity. The theme was chosen as it emerged during the more open scoping research of phase 1. Within this theme the role of mentoring as part of the school-based experience was also explored. A final focus group interview with subject mentors explored the key findings from the findings from the entire research project. The focus group interviews were mediated using a 'Fishbone tool' which is 'a mechanism to support the group interview process and the analysis of the resultant data into categories' (Hopkins, $2010 \mathrm{p}$.

43). This is achieved through enabling the researcher to carry out data reduction within the data collection phase using the input of the students 'to provide the validation of the derived analytic categories' (ibid. p.43).

\section{Phase One Scoping Research: PGCE: Student Cohort 1}

\begin{tabular}{|l|l|l|l|l|}
\hline Participants & Data collection method & Sample size & Analysis & Reference within text \\
\hline $\begin{array}{l}\text { PGCE Student } \\
\text { teachers }\end{array}$ & Focus group interview & $\mathrm{n}=11$ & Thematic & Students 1-11 \\
\hline Professional tutors & Telephone interviews & $\mathrm{n}=3$ & Thematic & $\begin{array}{l}\text { Professional Tutors 1- } \\
3\end{array}$ \\
\hline Subject mentors & $\begin{array}{l}\text { Questionnaires ( open- } \\
\text { ended questions) }\end{array}$ & $\mathrm{n}=5$ & Thematic & Mentors 1-5 \\
\hline Student teachers & Assignments & $\mathrm{n}=11$ & $\begin{array}{l}\text { Content } \\
\text { analysis }\end{array}$ & Students 1-11 \\
\hline $\begin{array}{l}\text { Professional tutors } \\
\text { (PT), University } \\
\text { tutors (UT) and } \\
\text { Research team (R) }\end{array}$ & $\begin{array}{l}\text { Shared reflections during } \\
\text { dissemination event }\end{array}$ & $\begin{array}{l}\mathrm{PT}=2 \\
\mathrm{UT}=4 \\
\mathrm{R}=2\end{array}$ & Thematic & $\begin{array}{l}\text { Professional tutor 1 \& } \\
2\end{array}$ \\
\hline Phase Two validation/extension phase: PGCE Cohort 2 & $\mathrm{n}=9$ & $\begin{array}{l}\text { Fishbone } \\
\text { tool }\end{array}$ & Students 12-19 \\
\hline $\begin{array}{l}\text { Student teachers } \\
\text { core subjects }\end{array}$ & Focus group & $\mathrm{n}=7$ & $\begin{array}{l}\text { Fishbone } \\
\text { tool }\end{array}$ & Students 20-26 \\
\hline $\begin{array}{l}\text { Student teachers } \\
\text { non-core subjects }\end{array}$ & Focus group & $\mathrm{n}=7$ & Thematic & Mentors 6-9 \\
\hline Subject mentors & Focus group & &
\end{tabular}

Table 1. Summary of data collection and analysis

\section{Results}

This section addresses the first research question; how do student teachers, their mentors and tutors experience mentoring, and what do they perceive as the affordances and constraints (including the influence 
of performativity) in creating a positive outcome? A start is also made in considering the second research question, how can mentoring be theorised as a practice; and to what extent might this support the participants in engaging positively in it?, through the results from the dissemination event and mentor focus group in particular. The results are collated from data from both phases of the research. What should be remembered about the mentors and professional tutors in this sample is that they often have experience of working with student teachers over a number of years, and as such may be drawing on a series of different mentoring relationships. This contrasts with the student teachers who can only reflect on their current experience.

\section{Affordances in mentoring practices}

Structures that underpin mentoring practices can act to support the process. Some of these structures are created at a school level, such as a schedule of training; others constitute a required component of mentoring within the PGCE partnership between the university and the school, such as weekly mentor meetings, experience of joint lesson-planning between mentor and mentee and regular observation; and some of them develop in the personal working routines of mentor and mentee.

One mentor described their mentoring pattern as follows, illustrating how it is built on, but not confined to, the routines of mentoring established as official structures by the PGCE partnership,

Formal mentoring meetings which would mainly comprise de-brief of lesson and discussing QTS standards and paperwork etc. - Informal ongoing mentoring dialogue around lesson planning, review of students, behaviour management etc (basically everything else!) This is ad hoc and takes place during free lessons, break, lunchtime etc - Working together during lessons - observing one another, providing additional support/ team teaching. (Mentor 3, questionnaire)

In addition to the official PGCE structures (such as the routines of lesson observation and review referred to above), the students also valued the school-based training organised within each school as the following extract form a cohort one focus group reveals:

...there are loads of teaching and learning strategies that they share with you and that they help you to develop. We've learnt so many different ways of doing things that we wouldn't have ever thought about before [Student 5 , focus group]

It's the training [Student 2, focus group]

Yeah once a week [Student 5, focus group]

The CPD's been incredible, incredible [Student 3, focus group] 
The driver for this additional training was articulated by one of the professional tutors and demonstrates the link between training and mentoring:

We have a plan for the full term based on the [...] criteria that comes from all universities but in addition for example [...] we had a couple of ITTs (student teachers) who were struggling with voice projection and really putting their stamp on the classroom so we arranged the drama teacher to do a session on voice projection [...] and they all benefit from that, so that's something I'll just pick up on from mentor meetings and observations. [Professional tutor 1, interview]

Joint-planning between student teachers and their mentors is a requirement of the PGCE course and is an aspect of their course which the students also have to reflect upon in an assignment. This structural component was reviewed positively throughout the data and the following is a typical comment:

[Joint lesson planning] has been a big part of my development and I think it will be the same for all people starting a teaching career. It becomes clear when talking to teacher that they have some ideas that they seem to just have in their head which over time you slowly learn and can start doing yourself. (Student 1, assignment)

Many mentors believe that a key part of their role is to manage the transition for the student from being a classroom observer, to participant observer, to co-teacher to teacher. Similarly there is sometimes a supported transition from the mentor taking the lead in mentoring discussions to the student having more autonomy. These represent a transfer from the mentor taking initial control in both lessons and mentoring to student having overall responsibility for their teaching and their own professional learning. This was recognised by a student as follows,

...My mentoring's had a really nice structure to it. When it started off it was like my mentor being sort of the leader of it and slowly that responsibility's got switched over to me, so it's me more bringing up my issues and discussing how I can sort of learn from it rather than it being very sort of directed in a way. So it's nice that sort of, because we expect a sort of responsibility transfer of independence in the student so that's kind of what I've gone through as a student teacher. I've learnt a lot from it. (Student 1 , focus group)

In addition to structures, participants also described the importance of relationship building in fostering positive mentoring outcomes. One student recognised the personal investment made by her mentor, but also her own reserve in engaging in mentoring, and a mentor noted how important the social aspect of the relationship can be.

My [mentor] has been absolutely fantastic, she's followed all the correct protocols. She's been there for you, on top of e mails, text messages, phone calls...one problem with me is that I don't come enough to her, I'm very much, keep myself to myself which is probably something that I've always done, no matter what age I was . $[\ldots]$ but she has been fantastic. (Student 8 , focus group)

Social: time spent getting to know the student, providing any support they might need or making sure they feel a part of the school and department (Mentor 3, questionnaire) 
Developing good relationships was thus seen as vital by both students and mentors with the sharing of personal stories representing to them that this had occurred.

ITTs feel vulnerable. The teacher gets to see them at their worst and their best, but they never get to see the teacher's 'worst.' The mentor needs to show how it is part and parcel of learning to teach. If the mentor discusses his/her own personal teaching journey this helps the student to see the mentor's vulnerability. (Professional tutor 1, comment during dissemination meeting with mentors, professional tutors, university tutors and research team)

\section{Constraints in mentoring practices}

Unsurprisingly all parties recognized that lack of time acted as significant structural constraint. This is because mentoring is an additional workload to the mentors' teaching roles, which are rarely adjusted to take account of mentoring. This issue is perhaps two-fold; firstly the perception of the burdens of the mentoring process (as one mentor noted - the 'onerous nature of the paperwork'), and secondly the fact that students and mentors can be time-jealous (a concept introduced by Billett, pers.comm., 18 ${ }^{\text {th }}$ November 2013). Time constraints can compromise what is most valued in mentoring by the participants.

Time is sometimes diverted into [paperwork] rather than genuinely useful discussion about progress and reflection. (Mentor 3, questionnaire)

A further variable which emerged from the data was that some mentors' additional roles (e.g. Head of Department) impacted on the access that student teachers had to mentoring time. This problem can be averted by decisions about who mentors (but this can of course affect the students' access to potential mentors with specific knowledge and skills), or it can be managed through informal distributive mentoring arrangements.

My mentor was slightly different, he's a head of department so he's slightly more busier, a bit harder to get a hold of, but if you do manage to catch him he's always happy to hear of any problems. [...] he's got other commitments, which I understand and in fairness he said to me that he didn't want me to feel neglected but he was already seeing me as part of the team and I could always go to other members of the department and that was no problem as well. (Student 4 , focus group)

You can also discount people in the department [for mentoring] who've got serious levels of responsibility because they're not going to have the time to do it properly. (Professional Tutor 2, interview)

In social terms, both the quality of relationships between mentor and mentee and the perceptions that they can develop of each other's responses towards the tasks in hand were identified as constraints to mentoring practice. Three of the 11 students in cohort 1 mentioned that they had not built up effective relationships with their mentors. In two cases this led to the students questioning whether or not to continue in teaching. 
I would say that I've obviously had my subject mentor and we've had the meetings every week and in certain situations we didn't always see eye-to-eye but I think it was more of a personality thing than a professional thing if you see what I mean, so sometimes it was kind of difficult for me to kind of go them. That's been a massive obstacle and every-one in this room knows how I've gone through that and it has been a massive obstacle in terms of my enjoyment I would say. (Student 5 cohort 1, focus group)

Similarly the mentors also revealed that relationships could be problematic:

The attitude of students can be difficult, if they are set in their ways and not willing to take advice or reflect upon their teaching it can make mentoring difficult. I also sometimes find students come into school not understanding the demands of teaching as a profession and possibly see it as a 'soft option'. (Mentor 2, questionnaire)

Students who are struggling may be resistant to mentoring or feel defensive. (Mentor 3, questionnaire)

It may well be that problems were arising as a result of misunderstandings by both parties. The emotional impact on the mentor as a result of the very personal nature of mentoring (particularly when a student is struggling) was also highlighted:

Although if somebody's letting down [the mentor's] classes and isn't learning or taking any advice they've still got to have some hard conversations and conversations where is it the right job for you? And if things aren't going well then there are often have to deal with tears, upset, where they're crying, I don't know if I can do this, I don't know if this is the right job for me, well for someone who's 27 and not very experienced that's quite tough on them. (Professional Tutor 1, interview)

A final constraint articulated by the student teachers was the nature of the feedback that they received through mentoring. Sometimes students felt that they received conflicting feedback which caused anxiety. In addition they received feedback that they perceive as overly critical. Some students attributed this to the quality of the relationship which sometimes led to a sense of professional inadequacy.

... then the school [mentor] observes me and I feel like the worst person in the world and it probably comes down to the whole clash of personalities thing again but I have had trouble with being able to speak to people because they make me feel like I'm rubbish. (Student 5, focus group)

Since I have took [sic] over classes from various teachers I will get feedback of different kinds from different opinions. Sometimes the advice can be overlapped or can contradict each other slightly which can sometimes make it hard to make a decision on what to actually do. (Student 9, assignment)

A further aspect of this was the perception of some students that their mentors were trying to 'mould' their students into the 'school way', and that this conflicted with the more general requirements of training to be a teacher. The following extract from a cohort one focus group demonstrates the conflict that this created:

I think an awful lot of the teachers in this school try to mould you into [school name] teachers (Student 2, focus group)

That's a fair point actually (Student 3, focus group) 
And when they're judging you and you're getting disheartened about things you've done, they're not requirements of an actual PGCE student, they're requirements of a [school name] teacher and their policies and procedures. (Student 2, focus group)

That's a fair point. (Student 3, focus group)

And sometimes I think they need to go back and ask if this is what is expected of them at this stage in a PGCE and not of what they should be doing in this school. (Student 2, focus group)

\section{The influence of performativity on mentoring}

The extract above illustrates the complexity of mentoring student teachers in schools in which performance activities have become prioritized, where school leaders are necessarily pre-occupied in maintaining or improving their inspection grade and position in league tables. This culture impacts on all teachers, who find themselves closely monitored and measured through lesson observations and through the examination performance of their classes. It is no different for mentors as they are first and foremost teachers. It is also no different for initial teacher training partnerships, which, as outlined in the introduction, are also subject to a strongly performative policy context. One result of this is the regular use of the terms 'good' and 'outstanding' as defined by Ofsted in relation to student teachers' practice. The impacts of this were explored in the second phase of research with both mentors and student teachers. The focus group discussions were started by sharing Hargreaves' (2000) definition of performativity; 'the performativity agenda can be characterised by itemisation and categorisation of teachers' work and recognition as checklists of performance standards or competencies' (p.152), and a question about whether this was recognisable as an influence on the PGCE.

In the mentor focus group it was felt that there had been a change over recent years in the students' attitudes towards their own progress and that this had affected the nature of mentoring. Mentor 6 asserted that 'it dominated the mentoring sessions, the performativity', and that the student teachers were now 'really quite obsessed with it, almost getting into a panic of getting various areas ticked'. This idea was developed by mentor 7 who said that 'it dominates the conversation that you have as well in terms of the pro-forma that's got to be filled in' indicating the pressure to 'come up with a sentence, to come up with a target'. The impact of this was noted by mentor 8 who felt that 'some weeks it's a good thing if maybe they've (the student) gone off on a tangent or haven't quite managed to meet their targets from last week, then other times I think it's quite, can be stifling'. An alternative perspective on practice was offered by mentor 9 who had recently 
completed a PGCert in Coaching and Mentoring during which the results from phase 1 of this research were discussed. She stated that during her mentoring 'the whole time I was thinking in terms of doing this course so I was aware of my own way of doing things' and that she did not see the purpose of mentoring meetings as filling the form in. She also reflected on whether this had been the concern of her student - noting that her first student teacher of the past year seemed happy to engage in extended conversation and retrospectively fill in forms, whereas her most recent student had compliance with form filling as her main focus. This theme was then developed by mentor 7 who recalled the following about her student, 'her personality was that she wanted to get everything done right, and do everything by the book, she was very conscientious and really wanted to prove that she'd done everything right and have evidence for that'. These focus group comments seem to confirm that the performative nature of the PGCE as a course, underpinned by the demand to collect evidence of meeting Teacher Standards, and to perform at a level described as at least 'good' in Ofsted terms, did affect the nature of mentoring practices.

This theme was also discussed in both student teacher cohort 2 focus groups (students 12-26). The opening responses to the trigger question on performativity illustrate this.

\footnotetext{
For me it's about sort of making progress towards the eight standards [...] and knowing that you can get feedback in from your mentor or other people on just whereabout you stand in relation to those standards I guess. (Student 12, cohort 2, core subject focus group)
}

I could link it from a school-based perspective to like your performance in the classroom and how well your kids are making progress and actually learn from the lesson, like trying to create a checklist and get feedback to know that you have to perform in the classroom. (Student 13, cohort 2, core subject focus group)

For me its links with the pressure on all teachers not just teachers at our stage who are constantly faced with the pressures to perform [...] whether that be in terms of exam grades or in terms of those standards. (Student 14, cohort 2, core subject focus group)

The tracking of evidence of progress and target-setting related to the Teacher Standards were seen as valuable by the students, with student comments like 'it's kept us on track, we've known what's expected of us' (student 15), and 'I had them all on every sheet and I could just see myself making progress' (student 16), 'it's a reference point isn't it' (student 13) and 'some of them you'd have evidence for but there might be one little section that you'd think I haven't really got enough evidence for that bit' (student 17). One student (with humour) concluded that 'it's frightening how fluent you become in it quite quickly' (student 18).

[The standards] help you to identify [...] what you need to improve so for instance assessment, I would teach lessons and think I could teach that lesson that's a good lesson, but then I would compare it to the standards and 
think hang on a minute I don't really think I assessed the pupils' progress effectively and I would identify key components where I need to start developing that more. (Student 21, cohort 2, non-core subject focus group)

Students in the focus groups articulated some concerns about the relationship between the use of Teacher Standards and mentoring practices, particularly reflecting on whether all mentors assessed progress towards the standards and forms of evidence in the same way, and whether they were being compared to other student teachers or directly to experienced teachers. Student 13 reported how the issue of her mentor grading her against standards had set up a tension from the start saying 'He's like well I'll tell you now I'll not be giving you that or that (referring to outcome grades) and I was like, ok, so that set us off on the wrong relationship'. The addition of student self-assessment of progress towards standards, created another variable that seemed to be responded to differently during mentoring, with students 17 and 18 admitting they struggled with it and student 19 stating that she ended up 'hedging her bets'.

The demands placed on teachers to be ready for external or internal quality inspections seemed to create a school-based culture which also seems to strongly influence mentoring. Both mentors and students reflected on this in the focus groups.

[The student's] a victim of Ofsted paranoia which we're all suffering from at the minute and she did that because she thought that was the right thing to do. [...] I think she picked up on the atmosphere within the school at the time which was that people were feeling very uncertain. [...] At the time I suppose her perception was that the school hoops were the same as the Ofsted hoops but are they really, or is it just our school's interpretation of what Ofsted want that was being filtered down? I felt at one point we'd gone too far down the straight line route of maybe not her copying my teaching and copying other people's teaching but doing set procedures that the school wants so she was conscientious to get those things in, she then found it quite hard to move outside those lines. (Mentor 9, focus group)

I've been under the pressure to deliver high standards cos like both my placements were in outstanding schools $[\ldots]$ so they set me the high standards they would set anyone and I quite like that because if you were in that environment that's the sort of pressure you'd be under. (Student 19, core subject focus group)

Students' experiences of teaching high stakes exam classes were also commented on, and access was often heavily managed by the mentor. Student 16 reported that she had experienced an attitude of 'don't go anywhere near Yr 11', student 18 'felt [she] was treading on people's toes' and went on to reflect 'I think it's really interesting $[\ldots]$ because the very first standard is set high expectations of your students but then if they're not [giving exam classes] to us how can we stretch ourselves?'. 
When questioned as to what types of 'school procedures' students might adopt uncritically all mentors in the focus group highlighted routines for checking pupils' progress in lessons. This led to an exchange which further illustrated some of the conflicts that mentors faced. Mentor 9 referred to this an 'ontological crisis', mentor 7 recalled trying to persuade her student to take more risks, and mentor 8 indicated that as a consequence of conflicting agenda she had felt positioned as a go-between.

I remember having conversations where I was trying to encourage the student [ ...] to be a bit more creative but they were sort of wanting to stick to schemes of work and I was saying the placement's about trying new things and thinking new ideas. (Mentor 9, focus group)

[The student teacher] did lots of creative things that she completely developed herself [...] but the agenda of progress and targets took over. She did get a bit obsessed with that, about progress, to the point where her final observation, the one with the tutor and an external assessor was criticised for being too much based on skills and not enough on actual subject context and, you know, where is the love of the subject, where is the passion for your subject. So that made her quite conflicted. [...] I was having to justify to the PGCE mentor and saying but that's not her fault that's because this is what the school currently thinks is the way to do it but it was ridiculous really. (Mentor 8, focus group)

A student offered a different perspective on a similar theme, which further illustrates how this can lead to dissonance in the development of practice.

It wasn't until the end of my weeks when I had to write a report that I thought about have they progressed and in one of my placements I was even told a child never gets less on their assessment than their last assessment, [...] so in a way schools are trying to make sure that their children are always showing progress even though maybe they're not. (Student 15, core subject focus group)

A final interesting discussion between the mentors hinged on the problem of labelling practice as outstanding.

In one case an interesting twist was offered when mentor 9 reflected that she worked in an 'outstanding

school' upon which the school's continued status as a newly accredited Teaching School rested.

... which means we [as teachers] have to be outstanding apparently and therefore are we less inclined to have those doubts with our student teachers because we don't, because we think we have to be outstanding and model how to be outstanding but then reflection is a big part of being outstanding as well so I think it would be shame if the ideal or the label of outstanding was to restrict conversation. [...] cos it meant you couldn't express doubts or you couldn't say well I had a rubbish lesson this morning because you can learn from both types of conversation. (Mentor 9, focus group)

\section{Discussion}

In problematizing the identification of best practices in mentoring, Brondyk and Searby, 2013, draw on the work of Kochan and Pascarelli (2012) who describe contrasting mentoring paradigms to categorize typical mentoring activities and terminologies. The paradigms they propose are 'traditional' (transmitting existing cultures and behaviours), 'transitional' (allowing for the emergence of creativity or innovation corresponding to new socio-cultural conditions) and 'transformative' (enabling a questioning of beliefs and routines and a 
consideration of how things might be, rather than how they are). They recognize that mentors may switch between paradigms according to the needs of their mentee. Our research suggests it is more complicated than that: the nature of the workplace as a host institution for mentoring, the personal experiences of the mentor in relation to their own professional learning; and the wider policy contexts within which mentoring is conducted are likely to be amongst other influencing factors.

Experiences of mentoring in this specific case study of initial teacher education vary but there are common constraints and affordances. Student teachers in England are expected to demonstrate good and outstanding outcomes in relation to each Teacher Standard as defined by the inspectorate. This dimension of work-place learning is what Billett (2011) refers to as occupational capacities, and the evidence from this case study suggests that this vocational outcome takes immediate priority. This is itself not a problem, except when it impacts on the wider, longer-term goal of helping students to develop sustained occupational competences (ibid.) which will fuel and scaffold further professional development throughout their career. Individuals' beliefs and institutional procedures intertwine to shape practices, influencing the nature of mentoring relationships, activities and conversations. For example, the pressure felt by the 'actors' in initial teacher education in the current policy context for the majority of student teachers to exit with an 'outstanding' grade is palpable.

Our research suggests that the wider value placed on mentoring within the workplace-orientated context of initial teacher education matters. It is not just learning in the workplace, but also learning for the workplace. Eraut (2007) highlights the roles of reflection, questioning and learning from mistakes; and Imants and Van Veen (2010) likewise note how reflection on work actions is critical in workplace learning, alongside opportunities for feedback and evaluation. There is some evidence that even within the relatively 'safe' oneto-one experience of mentoring these learning activities can be squashed. There is no single reason for this although Billett's concept of personal epistemologies held by both mentor and mentee can be seen as a critical component; taking into account the different attitudes, beliefs and approaches that are held and adopted by the participants. The socio-cultural context within which mentoring occurs also has a significant impact, as this can determine the nature and extent of learning and work-place processes (as defined by Eraut) which are made available to the student teachers, and indeed the extent to which the mentors are afforded the necessary 
time and mentor education to fulfil their role. Taken together the personal epistemologies and school context create what Billett refers to as the duality of the school placement experience for the student teacher, being dependent on both the quality of the invitation to learn from the workplace and the extent to which the learner chooses to engage. Mentors are part of the ecology of practice, and can improve student teachers' abilities to engage in workplace and learning processes. This was highlighted, for example, by the professional tutor who augmented the core training offer for students based on feedback from mentors about obstacles to their progress, thus altering the practice curriculum. It was also commented on in relation to the restrictions placed on student teachers with respect to gaining experience of teaching examination classes. Mentors, as key practitioners in the practice pedagogies of the workplace, can create productive and purposeful pedagogies which encourage students to both develop capacities for teaching and a proactive attitude towards experimentation, innovation, reflection and evaluation. Learning from mistakes is essential in a complex practice such as teaching, but some mentors even reported that they were unlikely to openly critique their own practice, thus modelling restrictive and protective conversation rather than expansive or dialogic mentoring.

The trend towards the practice of judgementoring, as identified Hobson and Malderez (2013), is illustrated through this case study, with students feeling judged against standards from very early in their school placements, and being expected to engage in self-surveillance too. While it is unrealistic to expect that that progress towards professional standards should not feature as a component of early career development, if it becomes a dominant discourse it can alter the balance of the mentoring ecology. A similar trend was found to occur in teacher coaching and was articulated through Engeström's Cultural Historical Activity Theory (CHAT) (Lofthouse and Leat, 2013). As in coaching it is possible that the strength of the dominant discourse, and indeed dominant activity, which is focused on performativity compromises procedures, practices and outcomes of mentoring. Wilson (2014) suggested (in her analysis of mentoring through CHAT), that 'if the main focus of mentoring activity is related to the community of the school, then the object [...] would appear to be that of pupil progress or curriculum coverage, rather than professional development of the student teacher' (p.24).

The case study suggests that mentoring in the workplace of schools is a vulnerable practice. To better understand the complexities and variability in mentoring it is useful to view it through the Theory of Practice 
Architecture (Kemmis and Heikkinen, 2012). In articulating the nature of the dimensions of physical/temporal, semantic and social spaces ('doings, sayings and relatings') in the mentoring in this case study, it is possible to determine major influences on it as a practice. Students and mentors do this intuitively, and recognise the inter-dependency of the spaces, but perhaps without grasping the significance of the dimensions in altering the quality of experiences and student teachers' professional learning outcomes. When evidence is offered back to participants in the partnership for review, the core concepts start to be revealed and the implications understood. It becomes clear to them that these 'spaces' are situated in the specific cultural and policy frames of the workplace, but also that each space is potentially malleable and that existing practices do not have to be endlessly repeated or remain unquestioned. A significant challenge in teacher education is how to make such conceptualisations of mentoring as a workplace practice more mainstream, when they are buffeted by a system driven by targets, standards and assessment regimes. It may be that reconceptualising mentoring as educational leadership (Thornton, 2014) is one way to make its conceptualisation and practice more sophisticated. This might offer it more status or priority within the ecology of the workplace; and thus allow productive mentoring practices to be privileged, with adequate time and professional development opportunities being provided to those undertaking the role.

\section{Limitations of this study}

Being interpretive in nature the study is undoubtedly influenced by the experiences of and challenges faced by the teacher-educator co-author. It could be criticised for using the data (which is limited in scope and scale by the case study methodology) to problematize mentoring within the workplace of schools at a time when the role of universities in teacher education in England is being constrained by policy drivers. By working collaboratively with a non-teacher educator as co-researcher and by engaging iteratively with mentors as part of the research process, it is hoped that a degree of objectivity is achieved. As the study is qualitative, generalizations should be understood on an analytical level, as it would not be possible to extrapolate our conclusions to other jurisdictions or even to other time-frames. The study does however capture experiences of specific individuals engaged in the key roles in teacher education at this point in time, and can be used to highlight tensions as well as opportunities. Thomas (2010) refers to case studies as the sources of 'exemplary knowledge' not because the example is taken as representative or a model, but because they can be 'viewed 
and heard in the context of another's experience (another's horizon) but used in the context of one's own (where the horizon changes)' and asserting that it is 'interpretable only in the context of one's own phronesis' (Thomas, 2010, p.31).

\section{Conclusions and implications for development of mentoring practices}

This study was undertaken at a time of policy transition for teacher training in England. The role of universities in initial teacher education is diminishing and schools are expected to take more direct responsibility for the selection of prospective teachers, their training and support. For the last two decades students have been mentored in their school placements, but the new policies place an increasing burden on teachers and their senior leaders engaged in this role as student teachers become more dependent on members of the school community to fulfil functions previously shared with university colleagues. At the same time fewer students will have the experience of being in a university cohort, with the potential loss of peer support. This may increase the tendency for experiences of mentoring to vary significantly, and may mean that stakeholders, in a more dissociated ecology, overlook the common constraints and affordances in developing positively perceived outcomes.

Given these developments there is a risk (evidenced in this research) that mentoring of student teachers in their prospective workplaces is vulnerable practice. For example the desired outcomes of mentoring may become more narrowly defined by the stakeholders, who are pre-occupied by the demands to meet the performance targets for both pupil achievement and compliance with teacher standards. This is not to deny the importance of the quality of new teachers' classroom practice, but this technical view may lead participants in teacher education to overlook the complex, iterative and relatively fragile processes which underpin initial teacher development.

Critically examining mentoring practice is now crucial for all 'stakeholders' to ensure that it offers a balanced and expansive learning experience for prospective teachers. By better understanding the alternative perspectives offered by participants in mentoring and those managing the process, and feeding the accounts of experience back in to the ecology of the initial teacher education partnership, it is hoped that more successful architectures of mentoring can be created. 


\section{References}

Brondyk, S. and Searby, L. (2013), "Best practices in mentoring: complexities and possibilities", International Journal of Mentoring and Coaching in Education, Vol. 2 No. 3, pp. 189-203

Ball, S.J. (2003), “The teacher's soul and the terrors of performativity". Journal of Education Policy, Vol.18 No. 2, pp. $215-228$

Ball, S.J. (2013) The Education Debate, The Policy Press, Bristol

Billett, S. (2011), "Workplace curriculum: practice and propositions", in F. Dorchy, D. Gijbels. Theories of Learning for the Workplace, Routledge, London, pp. 17-36

Burley, S. and Pomphrey, C. (2011), Mentoring and Coaching In Schools; Professional Learning through Collaborative Inquiry, Routledge, London

Clutterbuck, D. (2013), "Extending the research agenda on mentoring in education”, International Journal of Mentoring and Coaching in Education, Vol.2 No. 3, pp. 249-252

Cohen, L., Manion, L. \& Morrison, K. (2000), Research Methods in Education, $5^{\text {th }}$ Edition, RoutledgeFalmer: London

Department for Education, http://www.education.gov.uk/schools/leadership/deployingstaff/a00205581/teachersstandards1-sep-2012 [downloaded on 25th November 2013]

Engeström, Y. (1987), Learning by Expanding: An Activity-Theoretical Approach to Developmental Research, OrientaKonsultit, Helsinki.

Eraut, M. (2007), "Learning from other people in the workplace", Oxford Review of Education, Vol. 33 No. 4, pp. 403422.

Fletcher, S. (2000), Mentoring in Schools: A Handbook of Good Practice, Kogan Page, London

Fletcher, S. and \& Mullen, C.A. (Eds), (2012), The SAGE Handbook of Mentoring and Coaching in Education, Sage Publications, London. 
Hargreaves, A. (2000), "Four Ages of Professionalism and Professional Learning." Teachers and Teaching: History and Practice, Vol. 6 No. 2, pp. 151-182.

Hobson, A.J. \& Malderez, A. (2013), "Judgementoring and other threats to realizing the potential of school-based mentoring in teacher education" International Journal of Mentoring and Coaching in Education, Vol. 2 No. 2 , pp. $89-108$

Hopkins, E. (2010) “Classroom conditions for effective learning: hearing the voice of Key Stage 3 pupils” Improving Schools, Vol. 13 No.1, pp. 39-53

Imants, J., and Van Veen, K. (2010), “Teacher learning as workplace learning” In P. Peterson, E. Baker and B. McGaw (Eds), International encyclopedia of education ( $3^{\text {rd }}$ ed., Vol. 7, pp. 569-574). Elsevier, Amsterdam

Imants, J., Wubbels, T. and Vermunt, J.D. (2013) “Teachers' Enactments of Workplace Conditions and their Beliefs and Attitudes toward Reform" Vocations and Learning, Vol. 6 No.3, pp. 323-346

Kemmis, S., Edwards-Groves, C., Wilkinson, J. \& Hardy, I. (2012), “Ecologies of practices” In P.Hager, A.Lee \& A.Reich (Eds), Learning and Practice. Dordrecht:Springer

Kemmis, S. \& Heikkinen, H.L.T. (2012), “Chapter 14, Future perspectives; Peer-group mentoring and international practices for teacher development”, in Heikkinen, H.L.T. , Jokinen, H. \& Tynjala, P. (Eds) (2012) Peer-Group Mentoring for Teacher Development, Routledge

Kochan, F. and Pascarelli, J.T. (2012), "Perspectives on culture and mentoring in the global age", in Fletcher, S. and \& Mullen, C.A. (Eds), (2012), The SAGE Handbook of Mentoring and Coaching in Education, Sage, Los Angeles, CA, pp. 184-198

Limerick, B., Burgess-Limerick, T and Grace, M. (1996) “The politics of interviewing: power relations and accepting the gift”, Qualitative Studies in Education Vol. 9 No. 4, pp. 449-460

Lofthouse R., and Leat D. (2013) “An Activity Theory Perspective on Peer Coaching” International Journal of Mentoring and Coaching in Education Vol. 2 No. 1, pp. 8-20.

Miller, W.L. and Crabtree, B.F. (1999) 'Depth Interviewing’ in Crabtree, B.F. and Miller, W.L. (Eds.) Doing Qualitative Research Second Edition London: Sage Publications Inc. 
Thomas, G. (2011) "The case: generalisation, theory and phronesis in case study" Oxford Review of Education, Vol. 37 No. 1 pp. $21-35$

Thornton, K. (2014) "Mentors as educational leaders and change agents" International Journal of Mentoring and Coaching in Education Vol. 3 No. 1, pp. 18-31.

Timperley, H., Wilson, A., Barrar, H. \& Fung, I. (2007) Teacher Professional Learning and Development: Best Evidence Synthesis Iteration. Wellington: Ministry of Education.

Wilson, V. (2014) "Examining teacher education through cultural-historical activity theory” Tean Journal, Vol. 6 No. 1 , pp. 20-29

Yin, R.K. (2009) Case study research: Design and methods ( $4^{\text {th }}$ Edition), Thousand Oaks, CA: Sage 